\title{
Factores de crecimiento y periodoncia. Una revisión bibliográfica actualizada
}

\author{
IBERO SAGASTIBELZA I * \\ CASTRO LARA J * \\ BASCONES MARTINEZ A **
}

\begin{abstract}
Ibero Sagastibelza I, Castro Lara J, Bascones Martínez A. Factores de crecimiento y periodoncia. Una revisión bibliográfica actualizada. Av Periodon Implantol. 2002; 14, 3: 115-128.
\end{abstract}

\begin{abstract}
RESUIMEN
El presente artículo consiste en una revisión bibliográfica actualizada de los trabajos sobre la posible aplicación de los factores de crecimineto en la enfermedad periodontal y su terapeútica regenerativa respectivamente.

A raíz de los estudios revisados, in vitro primero e in vivo más tarde, y a falta de nuevos ensayos clínicos concluyentes, parece que esta técnica se presenta como una de las opciones más prometedoras en el tratamiento periodontal de los próximos años.
\end{abstract}

\section{PALABRAS CLAVE}

Enfermedad periodontal, factores de crecimiento, regeneración periodontal.

\section{INTRODUCCIÓN}

La enfermedad periodontal es una inflamación de origen bacteriano de los tejidos de soporte de los dientes. Consta de dos fases; la primera, denominada gingivitis, que se caracteriza por el componente inflamatorio, y la segunda, denominada periodontitis, que se caracteriza (además del componente inflamatorio) por una destrucción de los tejidos, y que es sobre la que nos vamos a centrar en este estudio.

El tratamiento de esta patología consiste en eliminar ese componente infeccioso, ya sea mediante técnicas mecánicas no quirúrgicas -raspaje y alisado radicular- o mediante la denominada cirugía periodontal. La aplicación de una o de otra depende de la severidad del proceso, y aunque el consenso entre los diferentes autores no es total, podemos establecer que la barrera que delimita la necesidad de la realización de una cirugía para la correcta y completa eliminación del agente microbiológico responsable de la periodontitis, es la presencia de bolsas periodontales de más de $5 \mathrm{~mm}$. de profundidad.
El problema que nos hemos encontrado hasta principio de los años 80 es que sólo se conocía la denominada cirugía resectiva, esto es, la eliminación de las bolsas periodontales sin recuperación de los tejidos dañados. Además de poseer unas características macroscópicas que muchas veces no la hacen ideal (sensibilidad de los dientes tratados por exposición radicular, aspecto poco estético...), este tipo de intervenciones conlleva una cicatrización que se ha comprobado a nivel histológico que tampoco es la más adecuada. Esta cicatrización de la que hablamos se denomina reparación, que podemos definir como la curación de la lesión por un tejido que no restaura completamente la arquitectura o función (1).

Pero a partir de los estudios de Melcher del año 1976 (2) en los que demostró que era posible obtener una curación a partir de los tejidos perdidos siempre y cuando evitáramos la repoblación de la superficie dañada por otras estirpes celulares indeseadas mediante barreras mecánicas, se introdujo el término de regeneración, que fue experimentada en humanos posteriormente por Nyman (3) y Gottlow (4), sien-

* Odontólogo. Alumno de doctorado. Especialista en Odontogeriatría UCM.

** Catedrático Medicina y Cirugía Bucofacial. UCM. 


\section{AVANCES}

Volumen 14 - No 3 - Octubre 2002

do este último el que acuñase el término definitivo que hoy conocemos como regeneración tisular guiada (RTG).

En el avance de la investigación de estos procesos reparativos se especuló con la posibilidad de no sólo inducir una respuesta del organismo, sino controlar y utilizar los sístemas mismos endógenos del organismo que se encargan de estas funciones.

Las primeras investigaciones se realizaron en medicina general, avanzándose en la caracterización de familias de señales moleculares que están involucradas en el control del crecimiento y diferenciación celular y, por consiguiente, poseen una función importante en el desarrollo de determinadas enfermedades como el cancer.

Particularmente importante ha sido el avance en el estudio de señales peptídicas, gracias al avance en biología molecular con las técnicas del ADN clónico (5), y que se han denominado factores de crecimiento, de importancia fundamental en la estimulación del mismo y en el mantenimiento de la viabilidad de una gran variedad de tejidos, que ha llegado a convertirlos en verdaderos principios generales de la biología del desarrollo.

De esta manera, podemos definir los factores de crecimiento como hormonas polipeptídicas cuya acción siempre es local, que regulan la diferenciación, la proliferación, la migración y el metabolismo celular (6) (7)(8). El uso potencial de estos factores es muy variado, y va desde la inmunoterapia del cáncer (interferón, interleukina-2) hasta el control de proliferaciones anormales (ciclosporina $\AA$ ), pasando por aquellos que más nos interesan en el campo de la periodoncia, como son la regeneración de los tejidos y la estimulación de la cicatrización.

Los primeros factores de crecimiento aislados y los primeros que se empezaron a utilizar en ensayos clínicos fueron:

- Factor de crecimiento derivado de las plaquetas (PDGF).

- Factor de crecimiento insulínico (IGF).

- Factor de crecimiento transformador (TGF).

- Factor de crecimiento fibroblástico (FGF).

- Factor de crecimiento epidérmico (EGF).

- Factor de crecimiento del endotelio vascular (VEGF).

El gran avance en este campo ha hecho que se hayan descubierto nuevas sustancias con una potencialidad similar a lo que podíamos denominar factores de crecimiento "clásicos", haciendo que la definición anteriormente citada quede algo obsoleta, por lo que hoy en día los autores prefieren referirse a los modifica- dores biológicos, familia que engloba los factores de crecimiento y nuevas sustancias descubiertas, y que podiamos definir como materiales o proteínas y factores con la capacidad potencial de alterar los tejidos del hospedador, estimulando o regulando el proceso de cicatrización de las heridas (9). Dentro de esta nueva definición se engloban sustancias como las proteínas óseas morfogenética (BMP) u otros factores de crecimiento como el factor de crecimiento derivado del cemento (CGF) o el factor de crecimiento de células del ligamento periodontal (PDL-CTX).

El objetivo del presente artículo es realizar una revisión bibliográfica sobre la función y posible aplicación de lo que hemos denominado factores de crecimiento clásicos en el ámbito de la Periodoncia.

\section{ASPECTOS GENERALES DE LOS FACTORES DE CRECIMIENTO}

\section{FACTOR DE CRECIMIENTO DERIVADO DE LAS PLAQUETAS}

Su descubrimiento se basó en la observación de que varios estudios habían informado que el plasma pobre en plaquetas era menos efectivo en la estimulación del crecimiento celular en cultivo (10). Se demostró que existía un polipéptido catiónico (más tarde se le acuñaría el nombre con el que hoy le conocemos) en el suero capaz de inducir el ciclo celular de la mitosis, y que estaba en función de la concentración del extracto de plaquetas (11). Más tarde se consiguió purificar dichas células, donde se almacena, ya que se sintetiza en los megacariocitos (11).

De igual manera se comprobó que se almacenaba en los gránulos-a (12) y que se liberaba durante la coagulación; siendo también producido, aunque en menor cantidad, por otras células como los macrófagos (13), las células endoteliales (14), los monocitos, los fibroblastos (15), el músculo liso y la matriz ósea (16).

En cuanto a sus características bioquímicas, se han purificado dos tipos diferentes de PDGF, denominados PDGF-I y PDGF-II, de un peso molecular de 35000 y 32000 daltons respectivamente y formados ambos por dos cadenas unidas por un puente disulfuro (17).

La actividad biológica de estos factores, de similar potencia en ambos casos, es mitógenica mediante la estimulación de la síntesis de $\mathrm{ADN}$, y actúan sobre las células de los tejidos conectivos, en especial los fibrobastos, las células musculares lisas y las células gliales. 
Tabla 1. Estudios clínicos más relevantes relacionados con factores de crecimiento y Periodoncia.

\begin{tabular}{|c|c|c|c|}
\hline Autory año & ipo estudio & ct. de crec. empleado & Hallazgos clínicos \\
\hline $\operatorname{Lynch}(1991)^{(57)}$ & In Vivo animal & IGF/ PDGF & Formación nuevo ligamento sin anquilosis \\
\hline \multicolumn{2}{|c|}{ Matsuda $(1992)^{(34)}$ In Vitro animal } & GF/TGF/PDGF/IGF & PDGF y PDGF+IGF factores más potentes \\
\hline Bartold $(1992)^{(45)}$ & In Vitro humano & PDGF & Inhibidor toxinas bacterianas \\
\hline \multicolumn{2}{|c|}{ Rutherford (1993) $)^{(60)}$ In Vivo animal } & PDGF & Sinergismo con dexametasona \\
\hline Blom $(1994)^{(38)}$ & In Vitro animal & EGF/PDGF/FGF & No tóxicos incluso en sobredosis \\
\hline Selvig $(1994)^{(63)}$ & In Vivo animal & IGF/FGF/TGF & Importancia vehículo de transporte y feedback \\
\hline Cho $(1995)^{(64)}$ & InVivo animal & PDGF & Coadyuvante RTG. Sinergismo ác. cítrico \\
\hline Park $(1995)^{(66)}$ & In Vivo animal & PDGF & Regenera $87 \%$ en furcas grado III \\
\hline Giannobile $(1996)^{(67}$ & In Vivo animal & PDGF/IGF & Mejor si se combinan factores de crecimiento \\
\hline Nishimura $(1996)^{(47)}$ & ${ }^{7)}$ In Vitro humano & PDGF/IGF/EGF/TG & Importancia de dosis adecuada \\
\hline Howell $(1997)^{(72)}$ & In Vivo humano & PDGF/IGF & $1^{\mathrm{er}}$ estudio. $42,2 \%$ regeneración $(2,8 \mathrm{~mm}$. \\
\hline Skeleric $(1997)^{(73)}$ & In Vivo humano & TGF & Importancia feedback "in vivo" \\
\hline Soory $(1999)^{(53)}$ & In Vitro humano & PDGF/TGF & Sinergismo con tetraciclina \\
\hline Oxford $(1999)^{(76)}$ & In Vivo humano & EGF & Importancia de órganos de almacenamiento \\
\hline Johnson $(1999)^{(75)}$ & In Vivo humano & VEGF & Importante factor "de inicio" \\
\hline Lee $(2000)^{(70)}$ & In Vivo animal & PDGF-FT & Vehículo de transporte con "sustantividad" \\
\hline Rossa $(2000)^{(71)}$ & In Vivo animal & FGF & Regenera furcas grado III (peor que PDGF) \\
\hline Palmon $(2000)^{(54)}$ & In Vitro humano & FGF & Potente regulador del colágeno tipo I \\
\hline Tatakis $(2000)^{(69)}$ & In Vivo animal & TGF & No efectivo en regeneración ósea periodontal \\
\hline $\operatorname{Gamal}(2000)^{(52)}$ & In vitro humano & PDGF & Dosis óptima aumentada no aumenta eficacia \\
\hline
\end{tabular}

PDGF: Factor de crecimiento derivado de plaquetas.

EGF: Factor de crecimiento epidérmico.

VEGF: Factor de crecimiento del endotelio vascular.

FT: Fosfato tricálcico
IGF: Factor de crecimeinto insulínico.

TGF: Factor de crecimiento transformador.

RTG: Regeneración tisular guiada. 


\section{FACTOR DE CRECIMIENTO INSULÍNICO}

A partir de la observación de que la supervivencia y el crecimiento de la mayoría de células indiferenciadas de los vertebrados, in vitro, dependían del suero exclusivamente, se aislaron nuevos factores de crecimiento. Uno de ellos se comprobó que poseía una estructura similar en un 50\% a la insulina (18) - de ahí su nombre-, con dos variante diferentes, la IGF-I y la IGF-II, de 7500 daltons aproximadamente cada uno, aunque nos centraremos en el primero, de mayor importancia en nuestro campo.

Se encuentran en diferentes tejidos, en mayor proporción en el hígado, corazón, riñón, bazo, cerebro y músculo liso; y en menor proporción circulando en el sistema vascular o por fluidos extracelulares transportado por unos complejos con proteínas específicas de unión (19) y son sintetizados por una gran variedad de células, incluidos el hueso y el cartílago. Su producción depende de la hormona de crecimiento.

En cuanto a su acción biológica principal es la formación ósea, ya que aumenta la síntesis de ADN en los osteoblastos y estimula la formación de matriz ósea, mejorando, por tanto, la proliferación de condrocitos.

\section{FACTOR DE CRECIMIENTO TRANSFORMADOR}

Fueron descritos por primera vez como factores de crecimiento de los sarcomas, ya que eran los responsables de la transformación reversible del fenotipo de los fibroblastos. Se purificaron dos tipos diferentes $(\alpha$ y $\beta$ ), y aunque inicialmente se pensó que se podrían extraer sólo de tejidos transformados, se observó que también se encontraban -en niveles más bajos- en tejidos normales (20).

Su peso molecular es de aproximadamente 5600 daltons en el caso del TGF- $\alpha$ y de 25000 daltons el TGF$\beta$. Tienen una gran relación con el EGF (sobre todo el segundo) y son sintetizados por una gran cantidad de estirpes celulares, tanto normales como transformadas; almacenándose principalmente en las plaquetas y en el tejido óseo.

En cuanto a sus acciones biológicas, el TGF- $\alpha$ posee efectos proliferativos tanto en fibroblastos y queratinocitos como en células epiteliales, de manera más potente que el EGF; circunstancia que se repite en su acción liberadora de iones calcio del hueso e inhibidora de la acción de los osteoclastos y, por tanto, de la reabsorción ósea. Por último, también posee un efecto angiogénico de neovascularización (21). Por lo que respecta al TGF- $\beta$, posee un papel bifuncional, con la habilidad de ser capaz de estimular e inhibir la proliferación de diferentes tejidos mesenquimales. Esta bifuncionalidad también se manifiesta en su forma de actuar, de forma sinérgica o antagónica, con otros factores de crecimiento (22). También cabe destacar su función en la matriz extracelular, en la fase de organización del colágeno, en la remodelación de la cicatriz; y un efecto angiogénico de mecanismo desconocido.

\section{FACTOR DE CRECIMIENTO FIBROBLÁSTICO}

Fue descubierto en 1940 cuando se informó que en el cerebro exitía gran cantidad de sustancias que estimulaban la división de los fibroblastos primarios en cultivo.

En primer lugar se purificó el denominado FGF básico, de entre 16000 y 18000 daltons de peso molecular, y más tarde se aisló el FGF ácido, de 15000 daltons (23), aunque actualmente se piensa que representan sólo a dos miembros de una gran familia de factores tróficos relcionados estructuralmente entre si. Ambos fueron encontrados en tejido neuronal, pero hoy sabemos que se sintetizan y se almacenan en numerosos tejidos que derivan del mesodermo y neuroectodermo o en aquellas células con un gran potencial angiogénico (24).

Su función está regulada por un gran número de moduladores como son la heparina o el sulfato de protamina; y consiste en una alta capacidad mitogénica para todas aquellas células derivadas del mesodermo, siendo además capaz de estabilizar la expresión fenotípica de las células en cultivo. De igual forma, tiene efecto en la diferenciación celular por su capacidad para controlar la síntesis y depósito de varios componentes de la matriz extracelular que son conocidos al afectar a la polaridad de la superficie celular y la expresión genética, como son el colágeno, la fibronectina y los proteoglicanos (25).

\section{FACTOR DE CRECIMIENTO EPIDÉRMICO}

Descubierto por Cohen en 1970 como un contaminante del factor de crecimiento nervioso y purificado totalmente en toda su secuencia en 1972 gracias a la gran cantidad de EGF presente en las glándulas salivales (26). Se sintetiza como un precursor muy pesado (133000 daltons), pero el factor de crecimiento funcional consta sólo de una cadena simple de aminoácidos con tres puentes disulfuro en su estructura de tan sólo 5500 daltons de peso molecular (26).

Existen una gran variedad de tejidos en los que se encuentra este factor de crecimiento, como son el esófago, estómago, duodeno e incluso en la orina y en la leche materna; pero solo se ha encontrado a la glándula submaxilar como la única fuente concreta de producción del EGF (27). 
En cuanto a su acción biológica tiene efectos proliferativos en fibroblastos, queratinocitos y células epiteliales, jugando un papel primordial en el desarrollo y erupción de los dientes. Sin embargo, también se ha comprobado su capacidad de inhibir la proliferación de algunos carcinomas de células escamosas (28). De igual manera tiene efectos importantes en la producción de elementos celulares especializados involucrados en la localización, movilidad y función de las células diana a las que afecta. Como ya se ha comentado antes, también posee una acción inhibidora de osteoclastos y liberadore de iones de calcio; y otra serie de funciones a nivel sistémico como pueden ser el desarrollo del aparato digestivo y el crecimiento craneofacial (29).

\section{Mecanismo de acción}

Para inducir un efecto biológico, un factor de crecimiento debe ser sintetizado por una célula originaria, desplazarse hasta su receptor diana, interactuar con dicho receptor o con una proteína captadora y activar los segundos mensajeros o efectores terminales (30).

Las sustancias endógenas del organismo pueden sintetizarse de cuatro maneras diferentes:

Endocrina: se secretan por un tipo celular y viajan a través de la circulación hasta una célula diana distante para ejercer sus efectos. Es característico de las hormonas y producen efectos muy extendidos porque se distribuyen por la circulación sanguínea y pueden acceder a numerosos tipos de células; al contrario que las sustancias de mecanismo de acción local -que son las que estamos estudiando-, que poseen tres tipos diferentes de síntesis.

Paracrina: una célula sintetiza un factor que interactúa con receptores presentes en otra célula del microentorno local. La primera célula secreta el modificador biológico en forma soluble y éste se une a los receptores de la célula diana para inducir sus efectos. Este es el sistema utilizado por factores como el PDGF o el TGF- $\beta$ (31).

Autocrina: son sintetizados por una célula y excretados en forma soluble al exterior de la célula, uniéndose después a receptores superficiales de la misma célula para inducir un efecto. Como ejemplo se pueden citar el TGF- $\alpha$ o las proteínas óseas morfogenéticas (BMP).

Yuxtacrina: son menos frecuentes y parecidos a los paracrinos, con la salvedad de que el factor sintetizado por la célula originaria se une a la superficie celular y tiene que establecer contacto celular con la célula diana para evocar una respuesta, siendo un ejemplo de esta mecanismo de acción las células progenitoras (32).

Intracrino: es el más excepcional, en el que una célula produce un factor pero no lo secreta, sino que actúa dentro de la misma para facilitar sus efectos, como por ejemplo ocurre con la hormona paratiroidea (PTH).

Una vez secretado, el factor de crecimiento debe unirse a su receptor, que debe encontrarse en cantidad suficiente y con la orientación y la actividad funcional adecuadas para poder transmitir los estímulos adecuados. En términos generales, se pueden dividir los receptores de los factores de crecimiento en dos categorías:

- Receptor celular superficial: es el más habitual, a su vez se puede clasificar en tres subgrupos,

- unidos a la proteína G (PGE, PTH)

- tirosina cinasas receptoras (PDGF, FGF, IGF)

- serina treonina cinasas receptoras (TGF, BMP)

Estos receptores superficiales se unen normalmente a factores peptídicos hidrosolubles, pero que no atraviesan con facilidad la membrana celular lipofílica.

- Receptor intracelular: suelen ser esteroides, como la vitamina D3, los estrógenos y los glucocorticoides. Se han encontrado receptores esteroideos en el citoplasma y en el núcleo de las células diana. Además, dentro del núcleo existen receptores intracelulares o proteínas captadoras para factores con un mecanismo de acción intracrino (33).

Una vez que el receptor superficial se une y se activa, una serie de segundos mensajeros se encarga de la siguiente fase en la inducción de una actividad biológica. Los cuatro segundos mensajeros más importantes son:

Adenilciclasa ( $A C)$, enzima activada por la proteína G, cataliza la reacción del trifosfato de adenosina (ATP) a monofosfato de adenosina cíclico (AMPc), que activa la proteína cinasa A y provoca la fosforización proteíca.

Fosfolipasa $C(P L C)$, que activa la proteína cinasa C para iniciar la fosforilación proteíca.

\section{Tirosina cinasa (TK),}

Serina treonina cinasa (STK), responsables directos de la fosforilación de sus proteínas diana.

La fosforilación proteíca es un componente esencial de la actividad de los factores de crecimiento, y es el responsable de los cambios que median en la proliferación y la diferenciación celulares, que son el distin- 
tivo de la actividad de los factores de crecimiento (34).

Una vez concluído este proceso comienza el ciclo de la proliferación celular, con el ciclo mitótico, que se divide en varia fases:

-) Fase S, en la que se sintetiza ADN

-) Fase M, en la que se divide la célula

-) Fases Gl y G2, de intervalo.

Los factores de crecimiento pueden actuar de dos maneras diferentes, la primera como un denominado factor de competencia, esto es, haciendo que la célula entre en el ciclo celular a partir de una fase de reposo denominada G0, como puede ser el PDGF; y la segunda como los denominados factores de progresión, que actúan una vez que las células adquieren la capacidad para iniciar el ciclo celular, por ejemplo el IGF. De igual manera, los factores d crecimiento regulan el resto del ciclo mitótico y el posterior proceso de diferenciación y maduración celular (35).

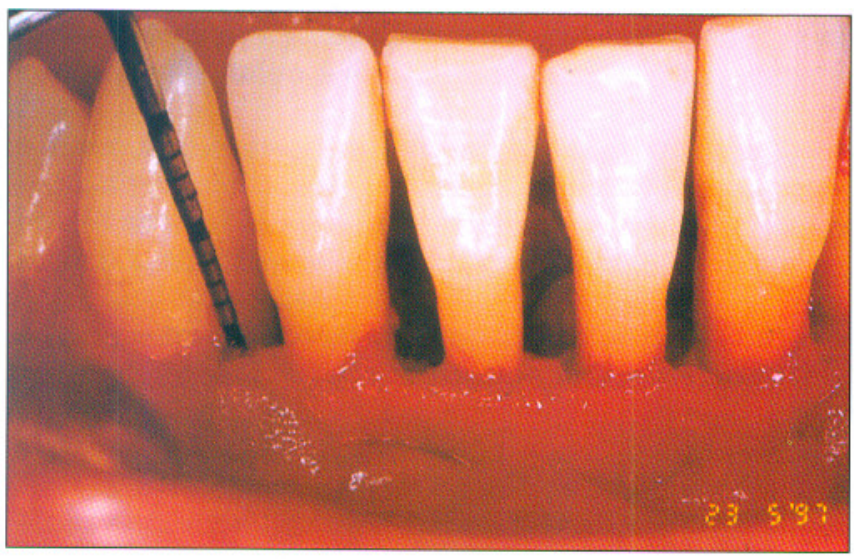

Fig. 1: Imagen clínica del defecto óseo vertical.

\section{FUNCIONES Y APLICACIONES DE LOS FACTORES DE CRECIMIENTO SOBRE EL PERIODONTO}

Como se comentó al principio, en la terapeútica periodontal actual buscamos la regeneración de los tejidos pérdidos. Podemos señalar que son necesarios por lo menos siete pasos para la restauración adecuada de la arquitectura y función del tejido periodontal:

a) Deben ser eliminados todos los elementos infecta- dos y degradados. El lugar debe estar libre de patógenos.

b) Deben estar próximas poblaciones de células progenitoras con la capacidad de la división celular.

c) Las células divididas deben, a través de un número apropiado de mitosis y de pasos diferenciadores, llegar a convertirse en células especializadas.

d) Las células especializadas y progenitoras deben migrar al lugar apropiado para la síntesis de la matriz.

e) En el lugar de la lesión, deben establecerse poblaciones celulares con capacidad para volver a repoblar los tejidos y que se mantengan en esa posición.

f) Los componentes de unión y de matriz deben ser establecidos integramente y someterse a una remodelación para restaurar la arquitectura y función tiular.

g) Las células repobladoras deben ser capaces de sintetizar factores de crecimiento para restaurar la homeostasis de la dinámica tisular.

En resumen, el tejido periodontal puede repararse y regenerarse por si mismo a través de los pasos anteriormente citados; y en todos ellos juegan un papel primordial los factores de crecimiento, por lo que los autores consideraron fundamental el estudio detallado de las funciones de estos factores secretados fisiológicamente por el organismo; y la posibilidad de fabricarlos artificialmente para utilizarlos allí donde fuese necesario, ya que, como comprobó Matsuda (36), las células fibroblásticas del ligamento periodontal poseen unas características especiales que les hacen receptores diana ideales a la acción de los factores de crecimiento, y que son:

- Un alto grado de polarización celular con una organización de sus organelas que tiene como resultado una mayor actividad sintética eficiente de los componentes de la matriz extracelular.

- Posee la más alta proporción obtenida en la síntesis de clágeno y la más eficiente polimerización de las nuevas moléculas colágenas recién formadas.

- Posee propiedades osteoblásticas.

- Su capacidad para involucrarse en la cementogénesis.

Para la mejor comprensión de la evolución de los ensayos clínicos realizados con factores de crecimiento, los hemos dividido en cuatro subgrupos: 


\section{a) Estudios con células animales in vitro}

Los primeros estudios de los que se tienen constancia datan del año 1988, en el que Koch y cols (37) demostraron la estimulación de la formación de la matriz ósea de la calvaria fetal de la rata tras la aplicación de IGF. Un año más tarde, Terranova y cols (38) y Tweden y cols (39) utilizaron el factor de crecimiento fibroblástico y demostraron como estimulaba la proliferación y la migración de las células del ligamento periodontal y las células endoteliales. Además, estos autores sugerían que el acondicionamiento de la superficie radicular, ya sea con clorhidrato de tetraciclina o con fibronectina provocaría una exposición del colágeno que facilitaría la adhesión e induciría la quimiotaxis de las células del ligamento periodontal.

Muy importante fue en el año 1992 el estudio de Matsuda y cols (36) sobre el EGF, el TGF, el PDGF y el IGF de forma individual y en combinaciones. Demostró que el subtipo PDGF-BB es el más efectivo sobre las actividades celulares de los fibroblastos periodontales como son la proliferación celular, quimiotaxis y síntesis de proteínas colágenas, obteniéndose su efecto máximo con dosis de $0,01 \mathrm{ng} / \mathrm{ml}$. El dato más revelador que obtuvo fueron los excelentes resultados de la combinación del PDGF y del IGF, en contra de lo que sucedió con las otras combinaciones estudiadas.

Otro estudio importante fue el realizado por Blom y cols en el año 1994 (39). En el se estudiaron conjuntamente el EGF, el PDGF y el FGF en células de rata cultivadas. La mayor aportación que realizó Blom fue la demostración de que los factores de crecimiento no influían en la morfología de las células fibroblásticas del ligamento periodontal aunque influían en las propiedades mitogénicas. Estos resultados se interpretaron como indicadores de la ausencia de los efectos tóxicos de los actores de crecimiento, incluso cuando están presentes a concentraciones suprafisiológicas.

En ese mismo año, Cho y cols (40) realizaron un estudio sobre la aplicación del PDGF en células de ratas demostrando que las células del ligamento periodontal tienen receptores para los tres diferentes dímeros del PDGF. Comprobó como el factor más potente es el PDGF-BB. De igual manera observó que el PDGF actúa además como factor paracrino al estimular ciertas células para secretar su propia producción de factores de crecimiento.

En el año 1997 Gianobille y cols (40) cultivaron células bovinas a las que le aplicaron diferentes combinaciones de factores de crecimiento (IGF+PDGF, IGF+TGF e IGF+FGF) obteniendo los mejores resultados en la primera de ellas. Este mismo autor sugiere que el hecho de que la aplicación de estas mismas combinaciones no obtenga los mismos resultados positivos in vivo se debe a que existe una regulación fisiológica del individuo en el que juegan un papel fundamental factores como el psicológico con la secreción de citoquinas proinflamatorias que contribuyen a la liberación de estirpes celulares presentes en la reabsorción ósea.

El último estudio que reseñaremos en este apartado es el realizado por Jiang y cols en el año 1999 (41) sobre células de rata cultivadas. En primer lugar compararon los efectos individuales del PDGF-BB y del IGF-1, llegando a la conclusión de que sólo el primero de ellos era absorbido y asimilado por la matriz ósea. Por otra parte estudiaron la importancia del vehículo transportador del factor de crecimiento, y sugirieron que el propuesto hasta ese momento -colageno- sufría un proceso de colapso que disminuía su potencial biológico regenerativo; por lo que abogaban por un material como el hueso liofilizado de origen animal, que además de evitar el colapso del

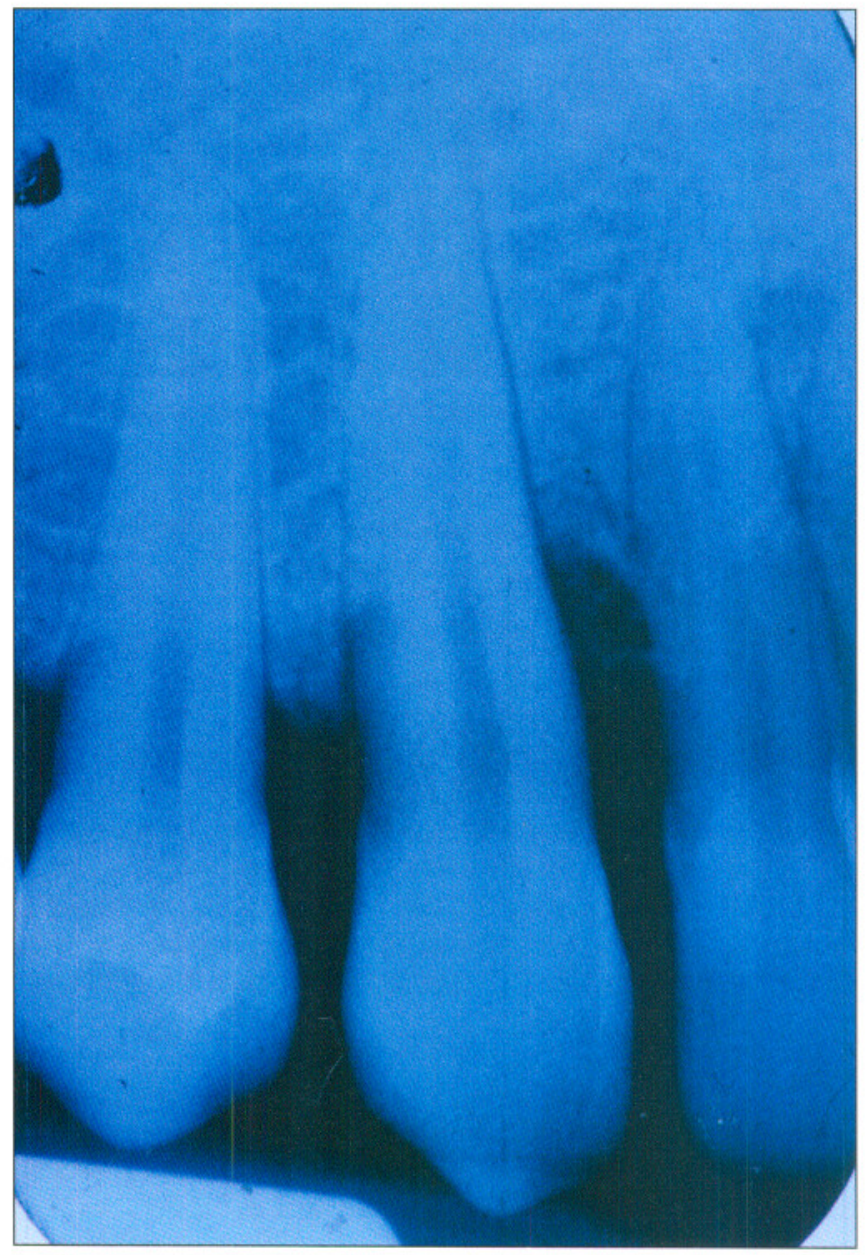

Fig. 2: Imagen radiológica de defecto ideal para ser tratado con RTG y FC. Preoperatorio. 


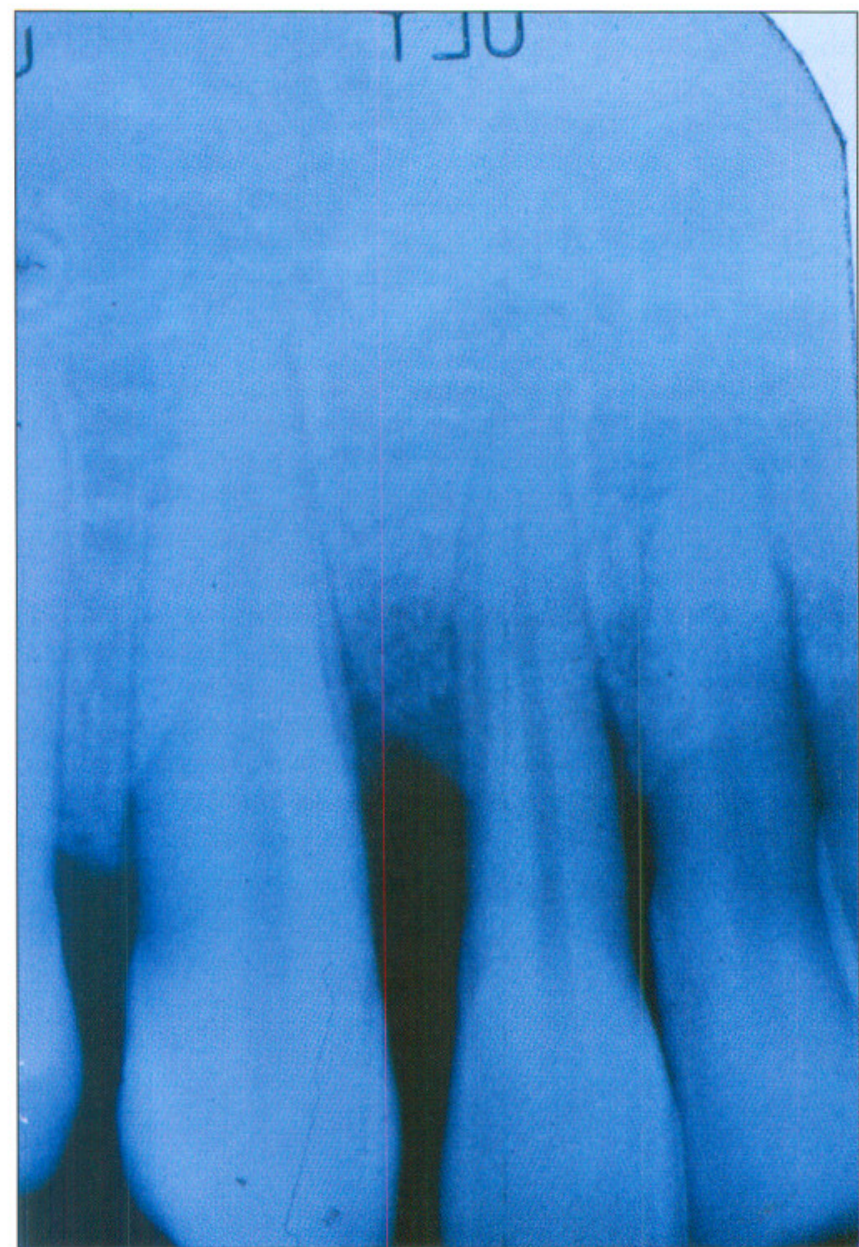

Fig. 3: Imagen radiológica del defecto óseo 6 meses después de la intervención.

lecho quirúrgico poseía una capacidad osteoconductiva beneficiosa en el proceso regenerativo.

\section{b) Estudios con células humanas in vitro}

Piche (42) fue el primero en demostrar que el PDGF estimulaba la proliferación de las células del ligamento periodontal y en ese mismo año Dennison y cols (43) llamaron la atención sobre la dosis adecuada a aplicar (10 $\mathrm{ng} / \mathrm{ml}$ en TGF y $20 \mathrm{ng} / \mathrm{ml}$ en PDGF) observando que los fibroblastos periodontales responden mejor a los FC que los fibroblastos gingivales.

Ya en 1993, Oates y cols (44) obtuvo unos resultados contrarios a lo publicado anteriormente, observando igual potencia en todas las isformas del PDGF y afirmando una débil mitogenicidad para el TGF.

En ese año, Bartold y cols (45) encontraron un hallazgo muy importante como es la afectación a la síntesis de hialuronidasas por parte del PDGF. Demostró como los productos bacterianos acumulados en las superficies radiculares impedían la prliferación de los fibroblastos y como este FC inhibía esa acción; ya bien por unión molecular aniónica o como factor de competencia.

Boyan y cols (46) contradijeron a Oates y (en concordancia con el resto de los autores) otorgaron a la isoforma PDGF-BB el mayor potencial mitogénico, mientras Nishimura y cols (47) demostraron una relación dosis-dependiente en la aplicación de diferentes FC (PDGF, IGF, EGF y TGF).

También se han realizado estudios en el campo de la biología molecular a este respecto, estudiando Parkar (48) el gen de la fibronectina y observando como las células periodontales sanas expresan corrctamente el gen en su totalidad, mientras que aquellas tomadas de pacientes enfermos no lo hacían, disminuyendo la producción de fibronectina y factores de crecimiento (PDGF, IGF, TGF).

De igual manera se ha estudiado cúales son las dosis más apropiadas, y así Kasasa y cols (49) comprobaron como de PDGF, IGF y TGF; dosis denominadas "óptimas" en estudios "in vitro" eran menos eficaces "in vivo" que otras más bajas, denominadas "subóptimas". De igual manera, Andersdon y cols (50) observaron el mismo hecho al darse cuenta que los factores de crecimiento cultivados en suero sin purificar (que tiene FC per se) eran menos eficaces que en suero purificado libres de ellos; llegando ambos a la conclusión de que la homeostasis fisiológica es fundamental en la actuación de los factores de crecimiento, produciendo un feedback de regulación de los mismos y entre ellos para su óptimo rendimiento. Esta misma conclusión es confirmada por Gamal y cols (51) en un estudio reciente, donde comprobaron que dosis de PDGF por encima de $50 \mathrm{ng} / \mathrm{ml}$ no eran más eficaces ni guardaban relación dosis/efecto sobre los fibroblastos del ligamento periodontal de superficies radiculares de dientes periodontales extraídos.

Los tres últimos estudios que remarcaremos en este apartado son los realizados por el propio Gamal (52), Soory (53) y Palmon (54). En el primero de ellos se estudió la eficacia de los FC sólos y en combinación y se llegó a la conclusión de que la aplicación conjunta de PDGF e IGF es la más beneficiosa, mejorando aún más el resultado si añadimos clorhidrato de tetraciclina, cuya desmineralización radicular no influía negativamente en los resultados. En el segundo observaron una acción antiproteasa de la combinación de PDGF y TGF con clorhidrato de tetraciclina; además de un sinergismo osteopromotor con los metabolitos androgénicos, lo que explicarí en parte la autoregulación 


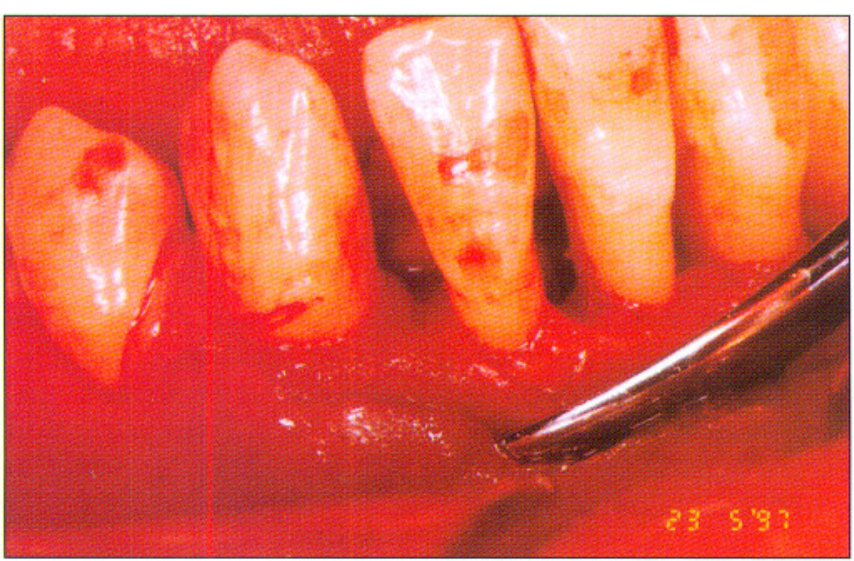

Fig. 4: Colocación de la membrana de RTG y el FC.

fisiológica. En el último estudio mencionado se remarca por vez primera la importancia del FGF como remodelador del colágeno tipo I y III, aumentando y disminuyendo la expresión de sus genes respectivos.

\section{c) Estudios in vivo con animales}

Tras los pioneros estudios de Srugel y McPherson en 1987 (55), se aplicaron in vivo en el campo de la Periodoncia, y así Lynch (56)fue el primero que aplicó un gel de PDGF e IGF en lesiones periodontales en perros obteniendo resultados positivos en tan sólo dos semanas de tratamiento. El mismo autor repitió el experimento doa años después (57) y llegó a la conclusión de que aunque la vida media de un FC es muy corta (4,2 horas para el PDGF), es capaz de estimular una cascada de hechos que continuaban incluso en su ausencia y que tenían como resultado la regeneración de los tejidos perdidos sin la parición de una obliteración o anquilosis del ligamento periodontal normal.

En ese año Eppley y cols (58) estudiaron la posibilidad de aplicar FGF de manera coadyuvante en el tratamiento con autoinjertos. En el grupo test observó una correcta cicatrización, mientras que en el grupo control se produjeron zonas de necrosis y secuestro óseo.

$\mathrm{Al}$ año siguiente Rutherford y cols (59) observaron en monos como la aplicación conjunta de PDGF e IGF regeneraba aproximadamente el $50 \%$ de los tejidos perdidos en 4 semanas e incluso en algunos casos inducía la regeneración del septo interdental en lesiones con pérdida ósea de tipo horizontal. Ese mismo autor (60) comprobó al año siguiente la acción sinérgica de los factores de crecimiento con la dexametasona, ya que ésta es el glucocorticoide más potente co-mitogénico que no afecta a las proteínas celulares

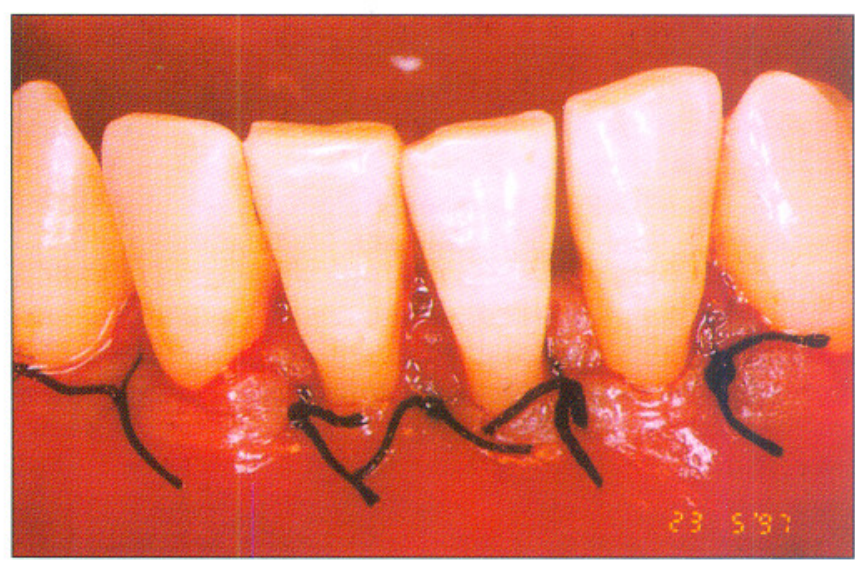

Fig. 5: Sutura.

o a la síntesis de colágeno in vitro, que además es antiinflamatorio y que puede estimular la formación ósea.

También es interesante el estudio realizado por Wang y cols en 1994 (61), en el que concluyó que no había diferencias entre la aplicación de FC úicamente -en el que los fibroblastos tenían origen gingival y del ligamento periodontal-, o en combinación con membranas de RTG -que los fibroblastos provenían sólo del ligamento periodontal; sugiriendo que aquellos de origen gingival no tienen el potencial regenerador de los otros.

Ese año, Giannobile y cols (62) estudiaron la respuesta inmunológica, microbiológica y de remodelación esquelética en perros/monos tras la aplicación de FC, obteniendo mejores resultados en los primeros, cuyo curso natural de la EP es más parecido a los humanos que los segundos, dando tiempo al efecto beneficioso de la homeostasis fisiológica; de igual manera que ocurriría en una hipotética aplicación en humanos.

Suguiendo con los estudios de ese año nos encontramos con el realizado por Selvig y cols (63) en el que no encontró diferencias significativas entre el grupo test y el grupo control tras la aplicación de IGF, TGF y FGF, explicando los autores un posible efecto inhibitorio de esta combinación; o una mala elección del vehículo de aplicación (colágeno fácilmente colapsable).

En esa fecha Cho y cols (64) demostraron in vivo sobre perros beagle el sinergismo entre FC (PDGF), membranas de regeneración y acondicionadores radiculares (ac. cítrico), obteniéndo un relleno óseo de hasta el $80 \%$, incluso superior a la aplicación exclusiva de membranas de RTG.

Schliephake y cols realizaron un estudio en 1995 sobre la formación ósea tras la aplicación de FGF (65) en cerdos enanos a los que se les colocaron implantes 
con injertos óseos subperiósticos cubiertos por membranas de RTG, y al no haber diferencias significativas con el grupo contol, concluyeron que el FGF tiene una débil acción osteogénica.

Un estudio similar lo realizaron Park y cols (66) sobre furcas de grado III tratadas con membranas de RTG con y sin la aplicación coadyuvante de PDGF-BB; obteniéndose respectivamente un 87 y un $60 \%$ de relleno óseo y observándose a nivel histológico una formación más temprana de tejido óseo inmaduro y una menor cantidad de tejido inflamatorio y de estirpe epitelial.

De igual manera realizaron un estudio sobre 10 primates Giannobile y cols (67) en 1996 aplicando PDGF e IGF individualmente y en combinación, siendo mejores los resultados en este caso, lo que demuestra que el PDGF actúa primero como factor de competencia, mientras el IGF actúa posteriormente como factor de progresión.

$\mathrm{Al}$ año siguiente Sculean y cols (68) observaron tras aplicar a un mono una membrana reabsorbible en combinación con PDGF la formación de fibras de colágeno apicocoronales a partir de fibras óxitalámicas que sólo se habían podido demostrar su existencia en las etapas formadoras de los tejidos de soporte del diente.

En el año 2000 se han realizado tres importantes experimentos a este respecto. En el primero de ellos Tatakis y cols (69) reafirman el escaso beneficio que proporciona la aplicación del TGF en defectos periodontales experimentales en perros, utilizando el carbonato cálcico como vehículo. En el segundo de ellos, Lee y cols (70) utilizan ratas para aplicar PDGF sobre esponjas de fosfato tricálcico en defectos óseos, demostrando un efecto osteógenico sin encapsulación de tejido conectivo, circunstancia que loa autores achacan a la aplicación de un vehículo correcto con "sustantividad". En el último estudio reseñado, Rossa y cols (71) regeneran furcas de clase III en 5 perros aplicando FGF y clorhidrato de tetraciclina y observan que -a dosis adecuadas de 0,5 mg- existe un importante relleno del defecto con tejidos mineralizados y no mineralizados.

\section{d) Estudios in vivo en humanos}

Tras unos resultados esperanzadores en animales, se comennzó a experimentar con humanos, y el primero en hacerlo fue Howell en 1997 (72) en el que es el ,hasta la fecha, el más importante ensayo realizado. Para ello seleccionó a 38 pacientes con lesiones periodontales bilaterales y los trató con una combinación de PDGF e IGF en dos formatos: un primer grupo con una dosis de $50 \mathrm{ng} / \mathrm{ml}$ en un gel de baja densi- dad, y un segundo con una dosis de $150 \mathrm{ng} / \mathrm{ml}$ en un gel de alta densidad.

Ningún paciente demostró reacciones adversas al tratamiento, encontrando en el segundo grupo un aumento de $2,08 \mathrm{~mm}$ de nuevo hueso con un relleno del $42,3 \%$ del defecto óseo, llegando incluso a regenerar furcas de hasta $2,8 \mathrm{~mm}$ de relleno óseo horizontal. Con este estudio demostró, por un lado, la eficacia y seguridad de la aplicación de FC en terapias regenerativas en humanos; y por otro lado, la importancia de factores tales como la dosis o el vehículo empleado en su aplicación.

Skaleric (73) realizó posteriormente un estudio combinado en perros/humanos, observando los niveles de TGF en la progresión de la enfermedad periodontal y viendo como, mientras en los humanos aumentaban los niveles según avanzaba la enfermedad en los perros ocurría lo contrario, concluyendo los autores (al igual que Giannobile que experimentó con animales) que mientras en el primer grupo la progresión de la enfermedad es lenta y da tiempo a una alimentación autocrina a partir de células de estirpe inflamatoria, en el segundo la EP experimental es demasiado brusca y no da tiepo a esa autorregulación.

$\mathrm{Al}$ año siguiente Booth y cols estudiaron por vez primera la importancia del factor de crecimiento del endotelio vascular (VEGF) en el curso natural de la EP (74). Sobre 32 pacientes enfermos y 12 sanos observó como, a pesar de que el voluman total de factor de crecimiento obtenida a partir del fluido crevicular era mayor en los pacientes enfermos; la concentración por unidad de voluman era mayor en los pacientes sanos, llegando a la conclusión de la importancia de la activiudad angiogénica en estados de salud y enfermedad; y en auellos procesos generales que cursan con alteración periodontal que cursan con la afectación de este FC, como son la diabetes y la neutropenia cíclica.

Hablaremos por último de dos estudios relizados en 1999. En el primero de ellos Johnson y cols (75) siguen en la línea citada y estudian los niveles de VEGF en 52 pacientes con diferentes estadíos de EP, encontrando mayor cantidad de dicho factor en aquellas localizaciones con enfermedad activa. También vieron como, mientras en aquellos defectos de menos de $6 \mathrm{~mm}$ la tasa de VEGF aumentaba en correlación con la severidad de la EP, cuando de sobrepasaba esta medida la tasa disminuía y ya no mantenía correlación con el grado de la periodontitis; ya que, según el autor, el VEGF es un factor neoangiogénico de inicio y progresión que se encuentra presente en salud y en los estadió iniciales de la EP.

El otro estudio lo realizaron Oxford y cols (76) sobre 37 
pacientes, 25 operados de un tumor parotídeo y 12 tratados con cirugía periodontal. En ambos observó un incremento de EGF en las primeras 48 horas que luego disminuía hasta los niveles normales; pero también destacó como -en contra de lo esperado por la mayor agresividad de la cirugía y el factor psicológico asociado- los niveles se muestran más altos en los pacientes con afectación periodontal, demostrando la importancia de la glándula parótida como reservorio de este FC (8:1 con respecto a las demás), alterando su síntesis la resección quirúrgica de parte de la misma.

\section{CONCLUSIONES}

Una vez realizada la revisión, podemos extrapolar una serie de conclusiones (77) (78):

a) A falta de nuevos ensayos clínicos, podemos afirmar que la aplicación de factores de crecimiento como coadyuvantes de terapias regenerativas es un procedimiento seguro y predecible.

b) Los factores de crecimiento que mejores resultados han obtenido han sido el PDGF-BB de manera individual y su combinación con el IGF en terapia combinada con membranas de RTG, no obteniéndose resultados tán positivos con la aplicación de otros factores de crecimiento.

c) Se deben tener en cuenta para la obtención de resultados satisfactorios, tanto circunstancias propias a la técnica quirúrgica (dosis, vehículo de transporte, acondicionamiento radicular y/o cobertura antibiótica, etc) como inherentes al propio paciente (autorregulación o feedback fisiológico).

d) Quedan abiertas futuras líneas de investigación como son la aplicación sitémica de factores de crecimiento, terapia génica para la manipulación de los genes reguladores de dichos factores, terapia celular con implantación de células productoras de factores de crecimiento, etc.

\section{ABSTRACT}

This paper consists in a preset complete review of the literature of the studies about the role and a possible apliccation of growth factors in the periodontal disease and its regenerative treatment respectively.

In order to literature analyzed, in vitro at first and in vivo later, waiting for new supportly studies, this tecniche seems as a hopoefull option in the periodontal treatment of next years.

\section{KEY WORDS}

Periodontal disease, growth factors, periodontal regeneration.

\section{BIBLIOGRAFÍA}

1. Messadi DV, Bertolami CH. Principios generales de cicatrización pertinentes al problema periodontal. Dent Clin North Am 1991; 35 (3): 441-53.

2. Melcher A On the repair potential of periodontal tissues. J Periodontol 1976; 47: 256-60.

3. Nyman S, Gottlow J, Karring T. The regenerative potential of the periodontal ligament. An experimental study in the monkey. J Clin Periodontol 1982; 9: 257-65.

4. Gottlow J. New attachment formation as a result of controled tissues regeneration. J Clin Periodontol 1984; 11 : 494-503.

5. Bronchud MH, Dexter TM. Clinical use of growth factors. BR Med Bull 1989; 45 (2): 590-9.

6. Caffesse R, Quiñones J. Polypeptide growth factors ans attachment proteins. Periodontol 2000 1993; 1: 68-77.

7. Caton JG, Greenstein G. Factors related to periodontal regeneration. Periodontol 2000 1993; 1: 9-15.

8. Lynch SE, Colvin RB, Antoniades HN. Growth factors in wound healing. J Clin Invest 1989; 84: 7696-700.

9. Laurie K, Somerman MJ. Modificadores biológicos en la regeneración periodontal. Dent Clin North Am 1998; 2: 377-404.

10. Antoniades HN. Human plateled derived growth factor (PDGF): Purification of PDGF-I and PDGF-II and separation of their reduced subunits. Proc Nat Acad Sci USA 1981; 78 (2): 7314-17.

11. Sitaras NM, Sarigan E, Patazis P, Zetter B, Antoniades HN. Human iliac artery endothelial cells express both genes encoding the chains of platelet derived growth factor (PDGF) and synthetize PDGF-like mitogen. J Cell Physiol 19876; 132: 376-80.

12. Rappolee DA, Mark D, Banda MJ, Werb Z. Wound macrophages exdpress TGF-a and other growth factors in vivo: analysis by mRNA phenotyping. Science 1988; 247: 70812.

13. Antoniades HN, Calanopoulos T, Neville-Golden J, Kiritsy $\mathrm{CH}$, Lynch SE. Injury induces in vivo expression of plate- 
let derived growth factor (PDGF) and PDGF receptor mRNA's in skin epithelial cells and mRNA in connective tissue fibroblasts. Proc Natl Acad Sci USA 1991; 88: 56569.

14. Hausschka PW, Mavrakos AE, Iafrati MD, Doleman SE, Klagsbrun M. Growth factors in bone matrix. J Biol Chem 1986; 261 (27): 12665-74.

15. Antoniades HN, Hunkapiller MW. Human platelet derived growth factor (PDGF): amino-terminal amino acis sequence. Science 1983; 220: 963-65.

16. Rinderknecht E, Humbel RE. Tha amino acid sequence of human insulin-like growth factor I and its structural homology with proinsulin. J Biol Chem 1978; 253 (8): 2769-76.

17. Clemmons DR. Structural and functional analysis of insulin-like growth factors. Br Med Bull 1989; 45 (2): 465-80.

18. Burgess AW. Epidermal growth factor and transforming growth factor. Br Med Bull 1989; 45 (2): 401-24.

19. Derynck R. Transforming growth factor a; structure and biological activities. J Cell Biochem 1996; 32: 293-304.

20. Roberts AB, Anzano MA, Wakefield LM, Roche NS, Stern DF, Sporn MB. Type b transforming growth factor: a bifunctional regulator of cell growth. Proc Natl Acad Sci USA 1985; 82: 119-23.

21. Baird A, Walicke PA. Fibroblast growth factors. Br Med Bull 1989; 45 (2): 438-52.

22. Gospodarowixz D, Neufeld G, Schweigerer L. Fibroblast growth factor; structural and biological properties. J Cell Physiol Supple 1987; 5: 15-26.

23. Cohen S, Carpenter G. Human epidermal growth factor: isolation and chemical and biological properties. Proc Natl Acad Sci USA 1975; 72 (4): 1317-21.

24. Buckley A, Davidson JM, Kamerathj CD, Wolt TB, Woodward SC. Sustained release of epidermal growth factor accelerates wound repair. Proc Natl Acad Sci USA 1985; 82: 7340-44.

25. Harper RA, Pierce J, Savage CR. Purification of human epidermal growth factor by monoclonal antibody affinity chromatogrphy. Methods Enzymol 1987; 146: 3-11.

26. Arthurson G. Epidermal growth factor in the healing of corneal wounds, epidermal woundss and partial-thickness scalds. Scand J Plast Reconstr Sug 1984; 18: 33-37.

27. Brown GL, Curtssinger L, Brightwell JR, Ackerman DK, Tobin GR, Polk HC, Nascimento CG, Valenzuela P, Schultz
GS. Enhacement of epidermal regeneration by biosinthetic epidermal growth factor. J Exp Med 1986; 163: 1319-24.

28. Howell TH, Martuscelli G, Oringer RJ. Polypeptide growth factors for periodontal regeneration. Curr Opin Periodontol 1996; 3: 149.

29. Lowry PA, Deacon D, Whitefield P. Sterm cell factor induction of in vitro murine hematopoietic colony formation by subliminal cytokine combinations. The role of anchor factor. Blood 1992; 80: 663.

30. Henderson JW, Amizuka N, Warshawsky H. Nucleolar localization of parathyroid hormone-related peptide enhances survival of chondrocytes under conditios that promote apoctotic cells death. Mol Cell Bio 1995; 15: 4064.

31. Watowich SS, Wu H, Socolovsky M. Cytokine receptor signal ttansduction and the control of hematopoietic cell development. Annu Rev Cell Dev Biol 1996; 12: 91.

32. McMahon SB, Monroe JG. Role of primary response genes in generating cellular responses to growth factors. FASEB J 1992; 6: 2707.

33. O'Keefe EJ, Pledger WJ. Amodel of cell cycle control: sequential events regulated by growth factors. Mol Cell endocrinol, 1983; 31: 197.

34. Matsuda N, Lin WL, Kumar NM, Cho MI, Genco RJ, Mitogenic, chemopatic and synthetic responses of rat periodontal ligament fibroblastic cells to polypeptide growth factors in vitro. J Perriodontol, 1992; 63 (6): 515525.

35. Koch G. Progenitor cell kinetics during guided tissue regeneration in experimental periodontal wounds. J Periodont Res, 1988; 23: 107-17.

36. Terranova VP, Odziemiec C, Tweden KS, Spadone DP. Repopulation of dentin surfaces by periodontal ligament cells and endotelial cells. Effect of basic fibroblast growth factor. J Periodontol, 1989; 60: 293-301.

37. Tweden KS, Spadone DP, Terranova VP. Neovascularization of surface demineralized dentin. J Periodontol, 1989; 60: 460-66.

38. Blom S, Holmstrup P, Dabeelsteen E. Acomparison of the effect of epidermal growth factor, plateled derived growth factor and fibroblast growth factor on rat periodontal ligament fibroblast-like cells'DNA synthesis and morfology. J Periodontol, 1994; 65: 373-78.

39. Cho MI, Matsuda N, Ramakrishnan Pr, Lin WL, Genco RJ. Differential regulation of periodontal ligamet cells acti- 
vies by plataled derived growth factor, insuline like growth factor-I and epidermal growth factor. Molecular pathogenesis of periodontal disease, 1994: 403-14. Washington DC: American Society for Microbiology.

40. Giannobile WV, Whitson SW, Lynch SE. Non-coordinate control of bone formation displayed by growth factor combinations with IGF-I. J Dent Res, 1997; 76 (9): 156978.

41. Jiang D, Dziak R, Lynch SE, Stephan EB. Modification of an osteoconductive anorganic Bovine bone mineral matrix with growth factors. J Periodontol, 1999; 70: 834-9.

42. Piche JE, Carnes DL, Graves DT, Initial characterization of cells derived from human periodontitis. J Dent Res, 1989; 68: 761-67.

43. Denninson DK, Vallone DR, Pinero GJ, Rittman B, Caffese RG. Differential effect of TGF-bl and PDGF on proliferation of periodontal ligament cells and gingival fibroblast. J Periodontol, 1994; 65 (7): 641-8.

44. Oates TW, Rouse CA, Cochran DL. Mitogenic effects of growth factors on human periodontal ligament cells in vitro. J Periodontol, 1993; 64: 512-25.

45. Bartold PM, Narayanan AS, Page RC. Plateled derived growth factor reduces the inhibitory effects of lipopolysaccharide on gingival fibrobast proliferation. J Periodontol Res, 1992; 27: 499-505.

46. Boyan LA, Bhargava G, Nishimura F, Orman R, Price R, Terranova VP. Mitogenic and chemotatic responses of human periodontal ligament cells to the different isoforms of plateled derived growth factor. J Dent Res, 1994; 73(10): 1593-1600.

47. Nishimura JF, Terranova VP. Comparative study of the chemotatic responses of periodontal ligament cells and gingival fibroblast to polipeptide growth factors. J Dent Res, 1996; 75: 986-92.

48. Pakard MH, Bakalios P, Newman H, Olsen I. Expression and splicing of the fibronectin gene in healthy and diseased periodontal tissue. Eu J Oral Sci, 1997; 105: 264-70.

49. Kasasa SC, Soory M. The effect of PDGF, TGF-b and IGF in combination on androgen metabolism by fibroblasts. J Clin Periodontol, 1998; 25: 640-6.

50. Anderson TJ, Lapp CA, Billman MA, Schuster GS. Effects of transforming groeth factor-b and plateled derived growth factor on human gingival fibroblasts grown in serum-containing and serum-free medium. J Clin Periodontol, 1998; 25: 48-55.

51. Gamal AY, Mailhot JM, Garnick JJ, Newhouse R, Sharawy
MM. Human periodontal ligament fibroblast response to PDGF-BB and IGF-l application on tetracycline HCI conditioned root surfaces. J Clin Periodontol, 1998; 25: 40412.

52. Gamal AY, Mailhot JM. The effect of local delivery of PDGF-BB on attachment of human periodontal ligament fibroblasts to periodontitis-affected root surfaces-in vitro. J Clin Periodontol 2000; 27: 347-353.

53. Soory M, Virdi H. Implications of minocycline, plataled derived growth factor and transforming growth factor-b on inflammtory repair potential in the periodontium. J Periodontal; 1999; 70 (10): 1136-43.

54. Palmon H, Roos J, Edel B, Zax N, Savion A, Grosskop A, Pitaru S. Inverse dose-and time-dependent effect of basic fibroblast growth factor on the gene expression of collagen type I and matrix metalloproteinase- 1 by periodontal ligament cells in culture. J Periodontol 2000; 71: 974-80.

55. Sprugel K, Mc Pherson J, Clowes A, Ros R. Effects of growth factors in vivo. Am J Pathol 1987; 129 (3): 601-13.

56. Lynch SE, Wiliams RC, Polson AM, Howell TH, Reddy MS, Zappa UE, Antoniades HN. A combination of plateled derived and insuline-like growth factors enhances periodontal regeneration. J Clin Periodontol, 1989; 16: 545-48.

57. Lynch SE, Ruiz de Castilla G, Williams RC, Kiristy ChP, Howell H, Redy SE, Antoniades HN. The effects of shortterm application of a combination of plateled derived and insulin-like growth factors factors on periodontal wouond healing. J Periodontal, 1991; 62: 458-67-

58. Eppley BL, Connolly DT, WinkelmannT, Sadove AM, Huevelman D, Feder J. Free bone graft reconstruction of irradiated facial tissue: experimental effects of basic fibroblast growth factor simulation. Plastic \& Reconst Surg, 1991; 88: 1-11.

59. Rutherford RB, Niekrash CE, Kennedy JE, Charette MF. Plateled derived and insulin-like growth factors stimulate regeneration of periodontal attachment in monkeys. J Periodontol Res, 1992; 27: 285-90.

60. Rutherford RB, Ryan ME, Kennedy JE, Tucker NM, Charette MF. Plateles derived growth factor and dexamethasone combined with a collagen matrix induce regeneration of the periodontium in monkeys. J Clin Periodontol, 1993; 20: 537-44

61. Wang HL, Pappen TD, Castelli WA, Chiego DJ, Shyr Y, Smith BA. The effect of plateled derived growth factor on the cellular response of periodotum: an autographic study in dogs. J Periodontol, 1994; 65: 429-36. 
62. Giannobile WB, Finkelman RD, Lynch SE. Comparison of canine and non-human primate animal models for periodontal regenerative therapy: results folowing a single administration of PDF/IGF-I. J Periodontol, 1994; 65: 1158-68.

63. Selving KA, Wikesjö UME, Bogle GC, Finkelmann RD. Impaired early bone formation in periodontal fenestration defects in dogs following aplication of insuline like growth factor-II, basic fibroblast growth factor and transforming growth factor b-1. J Clin Periodontol, 1994; 21 : 380-85.

64. Cho MI, Lin WL, Genco RJ. Plareled derived growth factor modulated guided tissue regenerative therapy with plateled derived growth factor. J Periodontol, 1995; 66: 52230 .

65. Schiliephake H, Neukman FW, Löhr A, Hutmacher D. The use of basic fibroblast growth factor (b FGF) for enhancement of bone in growth into pyrolized bovine bone. Int J Oral \& Maxilofacial Implants, 1995; 10: 181-86.

66. Park JB. Periodontal regeneration in class III furcation defects of beagle dogs using guided tissue regenerative therapy with plateled derived growth factor. J Periodontol, 1995; 66: 462-77.

67. Giannobile WV, Hernández RA, Finkelman RD, Ryan S, Kiristy CP, D' Andrea M, Lynch SE. Comparative effects of plateled derived growth factor-BB and insulin like growth factor-I, individually and in combination. On periodontal regeneration in Macaca fascicularis. J Periodontol Res, 1996; 31:301-12.

68. Sculean A, Karring T, Theilade J, Lioubavina N. The regenerative potential of oxytalan fibers, an experimental study in the monkey. J Clin Periodontol 1997; 24: 932-36.

69. Tatakis DN, Wikesjo UM, Razi SS, Thoraninn JS, Lee MB, Nguyen T, Ongpipattanakui B, Hardwick R. Periodontal repair in dogs: effect of transforming growth factor bl on alveolar bone and cementum regeneration. J Clin Periodontol 2000; 27: 698-704.
70. Lee CM, Park YJ, Lee SJ, Ku J, Han SB, Klokkevold PR, Chung CP. The bone regenerative effect of platelet-derived growth factor-BB delivered with a chitosan/tricalcium phosphate sponge carrier. J Periodontol 2000; 71: 418-24.

71. Rossa C, Marcantonio E, Cirelli JA, Marcantonio RA, Spolidorio LC, Fogo JC. Regeneration of class III furcation defects with basic fibroblast growth factor (b-FGF) associated with GTR. A descriptive and histometric study in dogs. J Periodontol 2000; 71: 775-84.

72. Howard Howell T, Fiorellini JP, Pffenbacher S, Giannobile WV, Lynch SE. A phase I/II clinical trial to evaluate a combination of recombinant human plateled derived growth factor-BB and recombinant human insuline-like growth factor-I in patients with periodontal disease. J Periodontol, 1997; 68: 1186-93.

73. Skaleric U, Kramar B, Petlelin M, Pavlica Z, Wahl SM. Changes in TGF-bl levels in gingiva, crevicular fluid and serum associated with periodontal inflammation in humans and dogs. Eur J Oral Sc, 1997; 105: 136-42.

74. Booth V, Young S, Crucley A, Taichman NS, Paleolog E. Vascular endothelial growth factor in human periodontal disease. J Periodont Res 1998; 33: 491-99.

75. Johnson RB, Serio FG, Dai X. Vascular endothelial growth factor and progression of periodontal disease. J Periodontol 1999; 70: 848-52.

76. Oxford GE, Johnson R, Olofsson J, Zelles T, Humphreysbeber MG. Elevated levels of human salivary epidermal growth factor after oral and juxtaoral surgery. J Oral Maxillofac Surg 1999; 57: 154-58.

77. García de la Fuente AM, Estefanía Cundin E, Aguirre Zorzano LA. Actualización sobre el uso de los factores de crecimiento y proteínas en el tratamiento regenerativo periodontal I. Periodoncia 1999; 9 (5): 341-54.

78. Serrano Cuenca V, Casas Hernández A. Factores de crecimiento: ¿un nuevo enfoque terapeútico?. Periodoncia 1997; 7 (2): 99-115. 